\title{
Amygdalin content in four stone fruit species at different developmental stages
}

\author{
Yu-ying Zhao \\ College of Horticulture and Gardening, Yangtze University, P. R. China \\ e-mail: zhaoyuying1212@163.com
}

Received 19 Nov 2011

Accepted 27 Feb 2012

\begin{abstract}
The amygdalin content of four species of stone fruit trees (apricot, peach, plum, and bitter apricot trees) during different stages was investigated by thin-layer chromatography. The results showed that the amygdalin content in the kernel was much higher than in pulps, roots, shoots, or leaves, and the highest amygdalin occurred in bitter apricot kernels. The patterns of amygdalin content in leaves of the four species consisted of a single peak curve, which increased from 30 April to 30 July, then started to decline reaching a lower level in October. In shoot and root, amygdalin decreased dramatically from 15 March to 15 May, then increased slightly until 15 December and maintained a relatively stable value. The tendency of amygdalin in xylem of stem and root was similarly a double peak curve, originally increasing from 15 March to 15 May, then decreasing to a low level, after that increasing slightly until December. However, the patterns of amygdalin content in shoots phloem was distinct from that of the xylem. The amygdalin decreased in shoot phloem whereas it increased in the stem xylem during the stage from 15 March to 15 July. The amygdalin content in root phloem and root xylem showed a similar trend with stem. Results demonstrated that amygdalin content in pulps and kernels was increased with the increasing in the leaves; the decrease in amygdalin in the phloem is connected with the increased in the xylem in early growth period.
\end{abstract}

KEYWORDS: pulps, roots, shoots, leaves, phloem, xylem

\section{INTRODUCTION}

Amygdalin is a commercially available natural cyanogenic glycoside occurring widespread in the seeds of Rosaceae ${ }^{1-4}$. Amygdalin consists of mandelonitrile lyase and gentiobiose. It is catabolized to $\mathrm{HCN}$, benzaldehyde, and D-glucose by the sequential action of amygdalin hydrolase, prunasin hydrolase, and mandelonitrilelyase ${ }^{5}$. Amygdalin is also found in the leaves and seeds of mature trees of several Prunus taxa: P. serotina, P. virginiana cv. Schubert of subg. Padus and P. ilicifolia and P. lyonii of subg. Laurocerasus $^{6}$. In seeds of Prunus serotina, amygdalin is stored in cotyledons and is catabolized upon germination to furnish the developing seedlings with reduced nitrogen and carbonyl compounds ${ }^{7,8}$. Wild almonds contain the cyanogenic glycoside amygdalin in the seeds and fruit pulp ${ }^{9,10}$. Amygdalin has been widely used in Chinese traditional medicine to treat asthma, aplastic anaemia, and tumours ${ }^{11,12}$. In addition, amygdalin affects seed dormancy and graft competency affecting replant and fastness of plants ${ }^{13,14}$.

The Merck Index, 13th ed., Merck Research Laboratories, Division of Merck \& Co. Inc., Whitehouse Station, NJ, USA, 2001. Peach (Prunus persica L. Batsch), plum (Prunus salicina Linn.), apri- cot (Armeniaca vulgaris Lam.), and Siberian apricot (Armeniaca sibirica Lam.) are the important species of Rosaceae fruit trees grown up in China. Previous studies demonstrated that amygdalin plays a key role in fruit trees physiology and is useful to humans $8,11,15,16$. It is interesting to study the changes of amygdalin in different parts of four stone fruit species to understand the regulation of such changes in the whole organ. Therefore, in order to determine whether amygdalin content varies with the seasons, this study examined the amygdalin content in fruits, leaves, stems, and roots of four species of stone fruit trees in order to understand its regulation during the period of growth. It might also be important to understand the biological roles and molecular mechanism to amygdalin synthesis. Besides, this study might promote the development of amygdalin application in Chinese traditional medicine.

\section{MATERIALS AND METHODS}

\section{Plant material and preparation}

The experiments were performed from March 2005 to December 2007. Samples were collected from 8-yearold trees of four different species: apricot, peach, plum, and Siberian apricot grew in an experimental 
orchard with same fertilizer program and irrigation at the college of horticultural and gardening, Yangtze University, Hubei province of China. All investigated trees (three trees per cultivar) were selected with similar size from the experimental orchard.

Fruits (30, one per replicate) used in these experiments were picked from periphery of crown with uniform colour, size, and without wounding between $15 \mathrm{~d}$ from 30 April to 30 June, and divided into middle mesocarp and seed. Seed-coats were excised and the kernel used for experiment. Leaf samples (50, one per replicate) were collected with the same age, uniform size, and without defects from middle of one-year old shoots in peripheral crown of a tree, picked every $15 \mathrm{~d}$ from 30 April to 15 October. The middle of nutritional shoots (20, one per replicate) were intercepted from one-year old shoots in peripheral crown of a tree every $30 \mathrm{~d}$ from 15 March to 15 December. Roots (20, one per replicate) were selected within $40 \mathrm{~cm}$ deep soil layer $(0.5 \mathrm{~cm} \leqslant$ diameter $\leqslant 2.0 \mathrm{~cm}, 10 \mathrm{~cm}$ length $)$ every $30 \mathrm{~d}$ from 15 March to 15 December. Sticks and roots were divided into phloem and xylem with a knife. All materials prepared were placed in an oven at $105^{\circ} \mathrm{C}$ for $15 \mathrm{~min}$ to inactivate the enzymes and then dried at $80 \pm 2{ }^{\circ} \mathrm{C}$. All dried materials were powdered by a subminiature plant mill (FZ102 subminiature mill, made in China) and screened with 60 mesh sieve. Dried powder was stored in a dryer.

\section{Methods}

The standards of amygdalin used for the experiment were purchased from China pharmaceutical biological product analysis institute, and other chemicals were analytical grade.

Extraction and determination of amygdalin were based on the procedure of thin-layer chromatography by $\mathrm{Hu}^{17}$. Chromatography conditions were as follows: $20 \times 20 \mathrm{~cm}$ silica gel $\mathrm{G}$ plate (Silica gel $60 \mathrm{GF}_{254}$, Qingdao, China), developer solution: butanol:acetic acid:water (95:5:25, v/v/v), colour developing agent: $4.5 \%$ hydroxylamine ethanol solution, and $1.25 \%$ ferric chloride methanol solution, dual wavelength, reflection, zigzag scanning $\lambda_{\mathrm{s}}=210 \mathrm{~nm}$, $S_{x}=7, \lambda_{\mathrm{r}}=370 \mathrm{~nm}$. $R_{\mathrm{f}}$ of amygdalin was 0.46 .

Standard solutions $(2.0 \mathrm{mg} / \mathrm{ml})$ of amygdalin were prepared in methanol prior to analysis. Standard solution with 5.0, 10.0, 15.0, 20.0, $25.0 \mu \mathrm{l}$ was positioned on the silica gel plate, respectively. After ascending development, staining, and drying, silica gel plates were scanned by CS-930 Dual wavelength TLC-scanning (Japan). Results indicate that the relationship between amygdalin concentrations and integral area was a linear relation in the range of 5.0-
$25.0 \mu \mathrm{l}$. The regression equation was $y=1.5113 X-$ 1.2504 (where $X$ was the amygdalin concentration $(\mu \mathrm{g} / \mathrm{l}) ; y$ was integral area; $r=0.9986)$.

To prepare specimens, $0.5 \mathrm{~g}$ sample powder was extracted with $5.0 \mathrm{ml}$ methanol in a $5 \mathrm{ml}$ flask. After soaking at $55^{\circ} \mathrm{C}$ hot water for $30 \mathrm{~min}$, the flask was taken out and placed at room temperature. Then, a $2 \mu \mathrm{l}$ of specimen extraction was positioned on the silica gel plate. After ascending development, staining and drying, silica gel plates were scanned by CS-930 Dual wavelength TLC-scanning (Japan).

\section{Statistical analysis}

Data were reported as mean \pm SD with triplicate determinations. ANOVA and least significant difference tests (SPSS for Windows, 1999, SPSS Inc., Chicago, IL) were conducted to identify differences among means. Statistical significance was declared at $P<$ 0.05 .

\section{RESULTS}

\section{Amygdalin content of pulps}

Changes of amygdalin in pulps are shown in Fig. 1a. During the season of growth, amygdalin contents in pulps of different species all increased, in apricot it increased from $0.52 \%$ to $3.12 \%$, in peach was from $0.29 \%$ to $2.29 \%$, in plum from $0.31 \%$ to 2.95 , and in Siberian apricot from $0.48 \%$ to $3.43 \%$ between 30 April and 30 June, respectively. The trend of amygdalin content in the four species was similar during the growth season. Besides, the amygdalin content of bitter apricot pulp was the significantly higher than that of the other three species $(P<$ 0.05 ) in measurement period, except in 30 April. In June, when fruits ripen and were harvested, amygdalin content of the four species in pulp all raised to the highest level.

\section{Amygdalin content of kernels}

The season variations of amygdalin content were similar in every species during the period of measurement (Fig. 1b). In developmental season (from April to June), amygdalin content increased in kernels of four species, apricot was $0.11 \%-3.26 \%$, peach was $0.13 \%-$ $3.73 \%$, plum was $0.28 \%-4.91 \%$, and bitter apricot was $0.39 \%-5.1 \%$. Amygdalin content markedly increased during May. There was a significantly high amygdalin content in bitter apricot kernel $(P<0.05)$ during the measurement period, except 30 April. In June, amygdalin content of all four species reached the highest levels with the ripeness of fruits. 

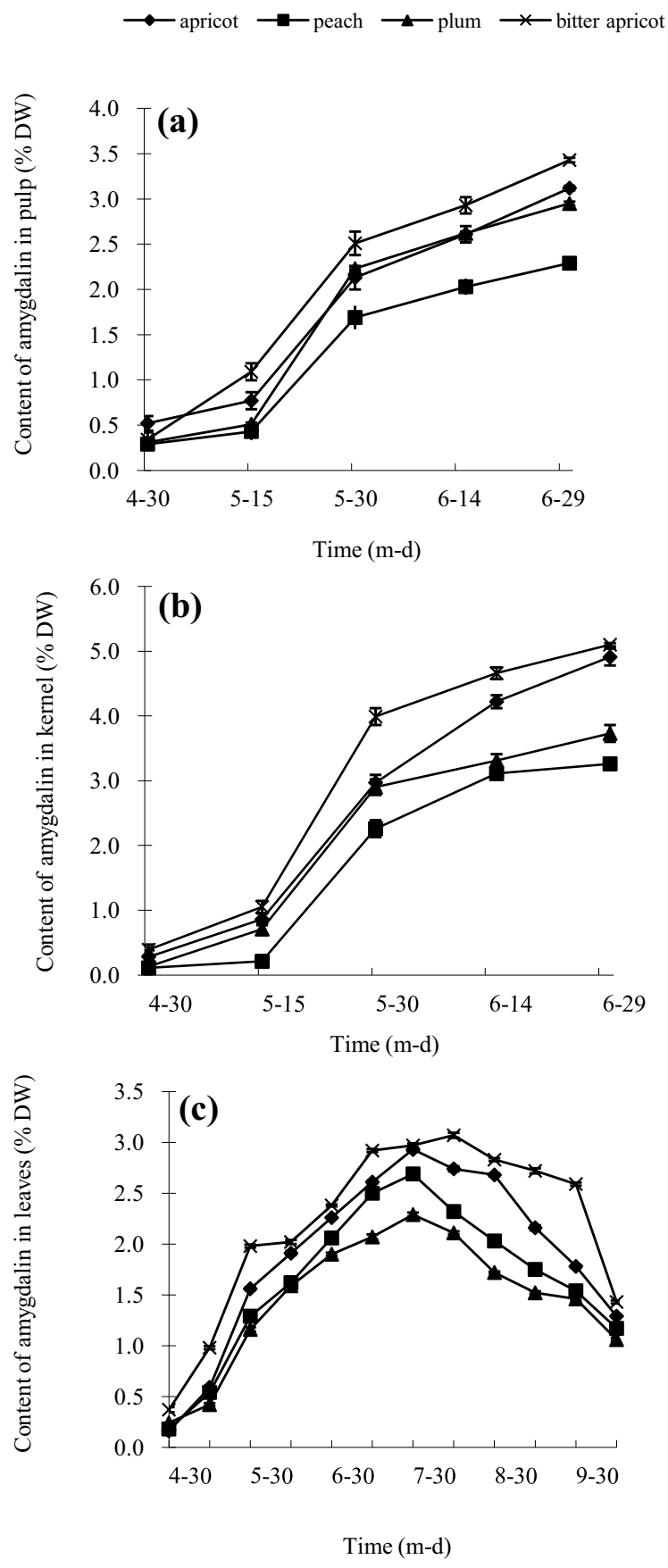

Fig. 1 Variations in amygdalin contents (\% DW) of (a) pulp, (b) kernel, (c) leaves in apricot, peach, plum, and bitter apricot leaves.

\section{Amygdalin content of leaves}

During the period from April to October, amygdalin content in leaves had a tendency to decline (Fig. 1c). The trend of amygdalin content in leaves was a single peak curve, which slightly increased from April to
July. There was a significant difference between bitter apricot and plum $(P<0.05)$. After 30 July, amygdalin content of all samples decreased reaching a lower level by 15 October. The amygdalin content of bitter apricot leaves was significantly higher than other three species and significant high amygdalin content appeared in leaves of apricot and bitter apricot, with no distinct differences between peach and plum. The amygdalin content in leaves decreased rapidly after 30 July. Up to 15 October, there was lower content in all species; however, bitter apricot amygdalin contents were still significantly higher than the other three species $(P<0.05)$.

\section{Amygdalin content of stem phloem}

Tendency of amygdalin in stem phloem were all double peak curves (Fig. 2a). The patterns of amygdalin seasonal changes of four species were similar from March to December. At the beginning of growth season (from 15 March to 15 May), the amygdalin content of stem phloem rapidly decreased reaching the lowest levels by 15 May. There were significant differences between bitter apricot and other three species $(P<0.05)$, but no significant differences between apricot and plum. The amygdalin content in stem phloem of the four species steadily increased from May to December. On 15 December, amygdalin contents of stem phloem reached their highest level without significant differences among four species of trees.

\section{Amygdalin content of stem xylem}

Amygdalin content in stem xylem of the four species followed a similar pattern over the same period (Fig. 2b). The amygdalin content rapidly increased from March to May reaching a peak in 15 May and then declined until July, afterwards increased from July to December. The highest value was observed in bitter apricot compared to other species among the same time of determination $(P<0.05)$. With the development of twig, the amygdalin content slowly increased from May to December remaining at a constant level.

\section{Amygdalin content of root phloem}

Seasonal variations of amygdalin in root phloem were all double peak curve pattern (Fig. 3a). Initially, the amygdalin content rapidly decreased from 15 March to 15 May, reaching the lowest value by 15 May, later rose gradually reached maximum by 15 December. The highest amygdalin content was found in bitter apricot throughout the determined period with a statistically significant difference $(P<0.05)$. 

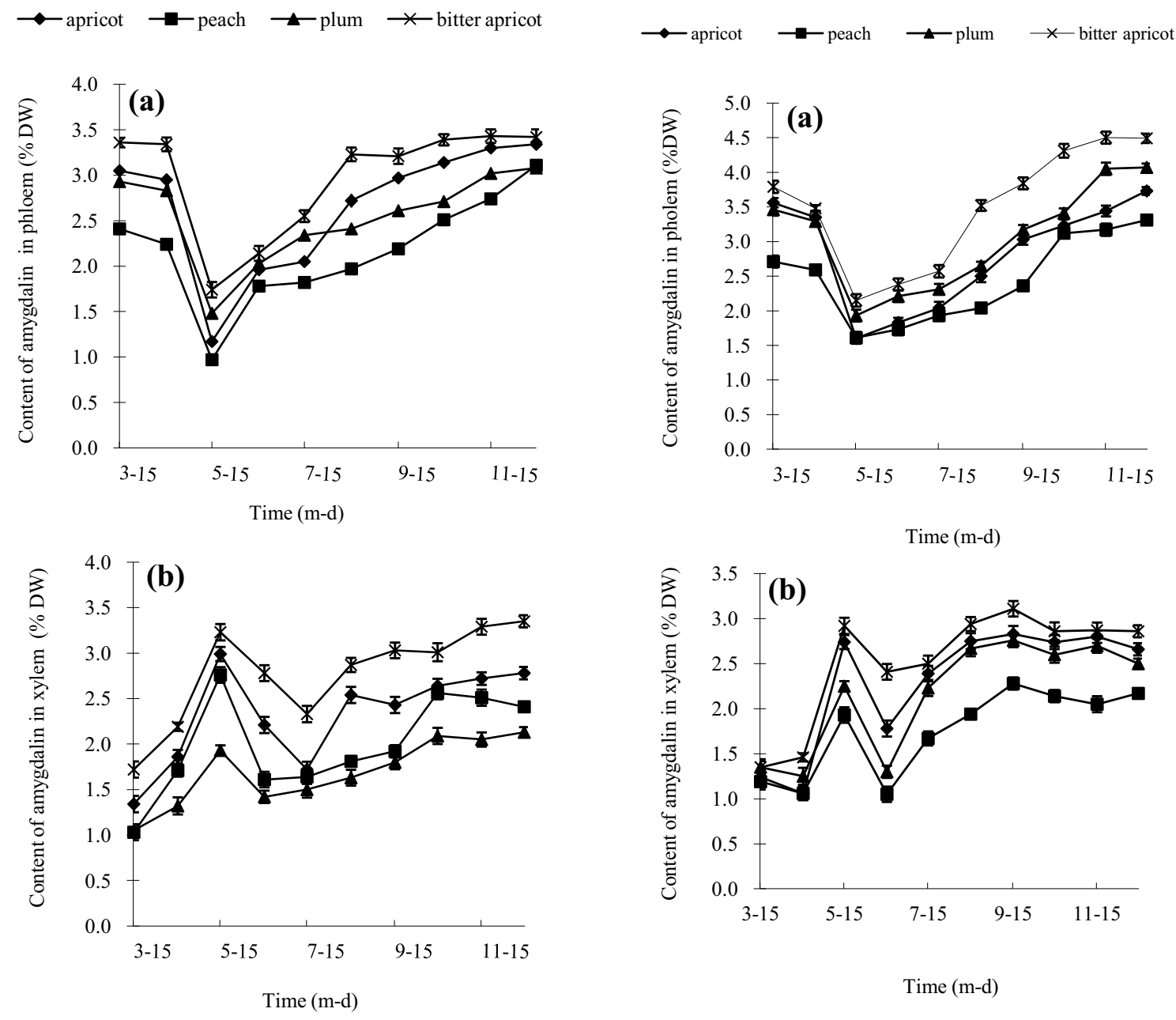

Fig. 2 Variations in amygdalin contents (\% DW) of (a) phloem, (b) xylem in apricot, peach, plum and bitter apricot stems.

\section{Amygdalin content of root xylem}

The overall seasonal trends of amygdalin in root xylem of the four species were observed in Fig. $3 b$. As with stem phloem, the content of amygdalin in root xylem increased rapidly from 15 April to 15 May reaching to the highest level by 15 May. Afterwards, amygdalin content declined reaching the lowest level by 15 June, and then gradually increased. From 15 August to 15 December, amygdalin content in root xylem of the four species reached their balance levels.

\section{DISCUSSION}

The dynamic changes of amygdalin content of the four stone fruit species were investigated in this study. With the development of fruits, the amygdalin level in pulps and kernels constantly increased reaching to

Fig. 3 Variations in amygdalin contents (\% DW) of (a) pholem, (b) xylem in apricot, peach, plum, and bitter apricot roots.

a peak value by the end of June. When the fruit was mature, the amygdalin content of kernel was higher than pulp in the four species (Figs. 1a, 1b). This result was consistent with studies of seeds in several stone trees ${ }^{18,19}$. The amygdalin accumulation in leaves coincided with the growth of leaves. Amygdalin content increased from 30 April to 30 July reaching maximum at the end of July, and then it gradually reduced to a lower level in the late growth stage (Fig. 1c). We speculated that the amygdalin was as a kind of nitrogen source and sugar compounds accumulated in early stage of leave development, and then transported to fruits when they developed. Amygdalin might be transferred to shoots and roots as a reserved nutrition $^{1,4}$. Therefore, amygdalin declines to a low level when leaves reach senescence. Variations patterns of amygdalin in stem phloem and root phloem were sim- 
ilar, rapidly decreasing from 15 March to 15 May, and then slightly increasing until 15 December to reach a relatively stable value (Figs. 2a and 3a). There were similar trends of amygdalin in stem xylem and root xylem, increasing rapidly until mid May to decline to lower levels in mid June with a slight increase up to December (Figs. 2b and 3b). However, the tendencies of stem phloem and xylem were different.

In our paper, we observed that amygdalin content in phloem quickly decreased in the early stages of growth in leaves. When leaves gradually mature, leaves synthesize much of carbohydrates and nitric compounds, which are transported and stored in phloem, thus amygdalin of phloem slightly increases. Previous evidence demonstrated that prunasin synthesized in the tegument is transported into the cotyledon via the transfer cells and converted into amygdalin in the developing bitter almond seed ${ }^{8}$. Our results are consistent with this, but the detailed mechanism is still not clear.

Acknowledgements: We are grateful to Dr Li-qin Cheng for sharing advice and experience.

\section{REFERENCES}

1. McCarty CD, Leslie JW, Frost HB (1952) Bitterness of kernels of almond 3 peach hybrids and their parents. Proc Amer Soc Hort Sci 59, 254-8.

2. Conn EE (1980) Cyanogenic compounds. Annu Rev Plant Physiol 31, 433-51.

3. Frehner M, Scalet M, Conn EE (1990) Pattern of the cyanide-potential in developing fruits. Plant Physiol 94, 28-34.

4. Dicenta F, Martínez-Gómez P, Grané N, Martín ML, León A, Cánovas JA, Berenguer V (2002) Relationship between cyanogenic compounds in kernels, leaves, and roots of sweet and bitter kernelled almonds. J Agr Food Chem 50, 2149-52.

5. Swain E, Li CP, Poulton JE (1992) Tissue and subcellular localization of enzymes catabolizing (R)-amygdalin in mature prunus serotina seeds. Plant Physiol 100, 291-300.

6. Santamour FS (1998) Amygdalin in Prunus Leaves. Phytochemistry 47, 1537-8.

7. Selmar D, Lieberei R, Biehl B (1988) Mobilization and utilization of cyanogenic glycosides. Plant Physiol 86, 711-6.

8. Swain E, Poulton JE (1994) Utilization of amygdalin during seedling development of Prunus serotina. Plant Physiol 106, 437-45.

9. Mizutani F, Okumura T, Amano S (1990) Changes in prunasin and amygdalin content in mesocarp, endocarp and seed of several peach species during development. Memoir Coll Agr 35, 91-8.

10. Swain E, Li CP, Poulton JE (1992) Development of the potential for cyanogenesis in maturing black cherry (Prunus serotina Ehrh.) fruits. Plant Physiol 98, 1423-8.

11. Culliton BJ (1973) Sloan-Kettering: the trials of anapricot pit. Science 182, 1000-3.

12. Fukuda T, Ito $H$, Mukainaka $T$, Tokuda $H$, Nishino $H$, Yoshida T (2003) Anti-tumor promoting effect of glycosides from Prunus persica seeds. Biol Pharmaceut Bull 2, 271-3.

13. Gur A, Cohen Y (1989) The peach replant problem: Some causal agents. Soil Biol Biochem 21, 829-34.

14. Esashi Y, Matsuyama S, Ashino H, Ogasawara M, Hasegawa R (1991) $\beta$-Glucosidase activities and HCN liberation in unimbibed and imbibed seeds, and the induction of cocklebur seed germination by cyanogenic glycosides. Physiol Plantarum 83, 34-40.

15. Selnard Liebert R, BeihLB (1988) Mobilization and utilization of cyanogenic glycosides. Plant Physiol 86, 711-72.

16. Mantre S (1989) The peach replant problem-some causal agents. Soil Biol Biochem 21, 829-34.

17. Hu RH (1995) Studies on content of amygdalin in Mahuang Decoction by TLC. Henan J Traditional Chin Med Pharm 10, 14-5.

18. Gómez E, Burgos L, Soriano C, Marin J (1998) Amygdalin content in the seeds of several apricot species. J Sci Food Agr 77, 184-6.

19. Ohtsubo T, Ikeda F (1993) Seasonal changes of cyanogenic glycosides in mume (Prunus mume sieb. et Zucc.) seeds. J Jpn Soc Hortic Sci 62, 695-700. 